\title{
Faith and End of Life in Nursing Homes
}

\author{
Robert L. Rubinstein, ${ }^{1}$ Helen K. Black, ${ }^{2}$ Patrick J. Doyle, ${ }^{3}$ Miriam Moss, ${ }^{2}$ and Sidney Z. Moss ${ }^{2}$ \\ ${ }^{1}$ Department of Sociology and Anthropology, University of Maryland, Baltimore County, Public Policy Building, 1000 Hilltop Circle, \\ Room 214, Baltimore, MD 21250, USA \\ ${ }^{2}$ Behavioral Research Institute, Arcadia University, 450 S. Easton Road, Glenside, PA 19138, USA \\ ${ }^{3}$ Doctoral Program in Gerontology, University of Maryland, Baltimore County, Public Policy Building, 1000 Hilltop Circle, 2nd Floor, \\ Baltimore, MD 21250, USA
}

Correspondence should be addressed to Robert L. Rubinstein, rrubinst@umbc.edu

Received 7 March 2011; Accepted 16 March 2011

Academic Editor: Laraine Winter

Copyright ( 2011 Robert L. Rubinstein et al. This is an open access article distributed under the Creative Commons Attribution License, which permits unrestricted use, distribution, and reproduction in any medium, provided the original work is properly cited.

This paper explores the role of religious belief in the experiences of dying and death in a Catholic nursing home. The home appeals to residents and their families due to the active religious presence. Thus, religion is a salient element of the "local culture" which exists in this long-term care setting. The preeminence of faith within the organization and the personal religious convictions of staff, residents, and families may drive how death and dying are discussed and experienced in this setting, as well as the meanings that are attached to them. This paper examines the relationship between faith and the experience and meaning of death in this nursing home. We present themes that emerged from open-ended interviews with residents, family members, and staff, gathered between 1996 and 2004. The data indicate that people select the home due to their Catholic faith and the home's religious tone. Themes also show that belief in God and an afterlife helps shape the experience of dying and death for our informants. Our paper does not compare ease of dying with other nursing homes or within other belief systems.

\section{Introduction}

There has been little research focusing on the attitudes and meaning of death for individuals who are surrounded by death and often confront thoughts of their own mortality, for example older adults living in nursing homes [1-5]. In addition, there have been few studies that examine bereavement experiences and psychological manifestations of loss that compare people of faith-however that might be definedto others [6-10]. For old age, such a comparison might be made more difficult by the imminence of losses of all sorts. For example, some families of people with Alzheimer's disease may see their loved ones sometimes as experiencing a kind of predeath prior to physical death $[11,12]$. However, and regardless of any such considerations, beliefs about dying in the presence of God are found in the nursing home that we discuss here. This is a Catholic institution in which a felt relationship with God is one feature in a panoply of sometimes diverse and paradoxical ideas about God, suffering, and dying.
One difference between how the death of loved ones is experienced by people of faith in comparison to nonbelievers is the issue of whether death is seen as a joyous transition [10]. The deceased is seen as moving on to a "better" place, that is a setting without disease and physical pain and suffering. In research described below, some informants, regardless of religious beliefs, described the death of a loved one as a positive in that it freed the person from physical pain. There was not a belief that physical pain experienced in life continued after death and no one in our study supposed that their loved one was moving on to some Hell in which they experienced continued pain. Perceptions of death and the afterlife, whether positive or negative, influence the experience of the dying process as well as the cognitions and emotions of those who observe that process [1]. Research shows that people with strong belief in an afterlife discuss dying as part of living and as an event that must be embraced and planned for in the way that a person prepares for any "next" stage of life $[9,13]$. Also, religiosity has been tied to a person's ability to confront existential issues 
and a personal fear of death [14], even if they are not fully resolved.

Our paper addresses the experiences of people who live through the death of a beloved elder in the religious setting of a Catholic nursing home. In our analysis, we specify several themes that are commonplace in residents' and family members' discussion of what death in the nursing home means to them.

\section{Methodology}

The data described in this paper were gathered in a NIAsupported research project titled "Bereavement in LongTerm Care" which was undertaken from 1996-2004. In the initial four years of the project we examined the social and cultural construction of the experience of death and dying in four ethnically_or religiously_identified not-for-profit nursing homes. The research methods were qualitative and ethnographic and involved in-depth key informant interviewing and participant observation. One main question addressed the significance (or lack) of cultural differences in the understanding and treatment of death and dying in each of these settings. The overall aim was to better understand what it is like to die as well as to live in an environment where death is commonplace. For the sake of anonymity we provide only scant details of the setting, which was a large, Catholic nursing home in North America. This nursing home was on a campus with other sorts of residential care settings and ancillary services for the elderly. The nursing home portion of the setting featured the standard nursing home elements such as administrators, CNAs, nurses, visiting physicians, housekeeping, and dietary staff and was visited regularly by nuns. The Home retained a priest dedicated to offering daily Mass for all residents. The facility was attractive to those who considered Catholicism significant in their lives. Family members felt assured that this Nursing Home was appropriate for their deeply religious loved ones, even when the elders were unable to speak for themselves.

For the purposes of this paper we reviewed more than 100 documents which represented either exact transcripts of research interviews or case summaries, field observations, or field notes resulting from research interactions. For this portion of our overall research, we spent about eight months in the field. The interviews were conducted by project field staff with cognitivelyable residents of the nursing home portion of the field site, with family members, and with staff concerning their perceptions of death and dying at the nursing home. One interesting observation is that interviews held with the religious sisters who were attached to the nursing home as helpers or as relatives of residents were notably free of religious talk, focusing primarily on residents' need for comfort and care.

\section{Results}

The process of coding, which required several close readings of text, enabled us to sort informants' responses to our questions into content areas as well as to identify and label large areas of meaning which we discovered as we reviewed text after text. Four of these content areas, or themes, were found pervasively throughout the texts that we reviewed: (1) death optimism or positive aspects of death and dying, (2) discourse (or lack of discourse) about death and dying, (3) role of personal beliefs and virtues in confronting death, (4) experiences with death and dying.

A search for meaning in the life and death of the elderly resident is the basis for the themes we discuss. Within these thematic categories, subthemes are also offered.

\subsection{Theme One: Death Optimism or the Positive Aspects of Death and Dying}

3.1.1. The Presence of God in Dying and Death. The subtheme of the presence of God in dying and death was often mentioned by residents, staff, and family members. It seemed to pervade the environment, where people self-selected to reside in a nursing home that was religiouslyidentified and organized. It appeared that residents and family chose this setting because they were religious Catholics who searched for a residence that was compatible with their deep, usually long-held, beliefs. In other words, the religious focus added a dimension to the elder's life that was appropriate to their stage in life and would be absent in other settings. For example, among the approximately 100 people we interviewed at this nursing home was a nun whose mother was dying in the nursing home. This religious sister said of her own work, "In my ministry I visit everybody, young and old, whatever. I have experienced young people dying of cancer and that's terrible. But all the people know the Lord is with them, the ones I have visited. They have great confidence in the presence of God, which overwhelms me and leaves me in awe." Her impression of trust in God among the dying was also prevalent among nonclergy. Affiliation with this setting was a deliberate attempt to make the life and death of the resident meaningful.

The reason family members brought their loved one to this nursing home was for the quality of care they envisioned-or knew from prior contact-that they would receive. Underlying this care was the family member's attempt to make the end of life meaningful. Although some residents and family members did not adhere to the entirety of Catholic doctrine, the nursing home environment was one in which Catholic principles and attitudes prevailed. Residents reported that daily Mass was one of the most comforting features of their routine. Some residents would arrive early in their wheelchairs and move to their customary places in the large chapel. For the devout, God is present in every aspect of living and dying and it is in this light that we interpret experiences of suffering in the nursing home. Some residents felt that suffering was to be borne; they used the example of the passion of Christ as a model. For some residents and family members, their suffering had a purpose at the end of life. It may be that suffering could be used as an intercessory prayer for another, or that they would reach a level of intimacy with Jesus through shared suffering, or perhaps that they would reach Heaven more quickly, 
through their sufferings on earth. Others, however, saw this differently and viewed suffering of any sort to be avoided at all costs. Avoidance, however, did not necessarily mean that informants believed suffering was without purpose. To be without purpose did not mean, to a believer, that suffering had no meaning.

3.1.2. Ending Suffering. A theme related to the presence of God at death and dying is that of ending suffering. Residents, family members, and staff discussed suffering without any reference to suffering as the activity of God. That is, suffering holds a negative value and is not compatible with the nature of God except when God acts to relieve suffering. For informants, it appeared that suffering falls under the domain of humankind, yet with no clarity for understanding or interpretation. Suffering is inchoate; it is "out there" without rationality. Only one thing is certain: God does not cause suffering; God is the loving power who relives suffering and to whom one owes gratitude for this relief. The sister of an elderly resident noted, "I thank God they removed his leg. It was good for him, he suffered enough. We thought it was better for him because he was suffering." Here, leg removal, a radical step in any circumstances, is thought of as a relief from suffering. Unfortunately, this resident also endured Alzheimer's disease, which muddled the issue of suffering in the mind of the family member because, even after removing the cause of intense physical suffering - the leg-the resident continued to suffer; he lacked a sense of his identity and integrity as a person.

3.1.3. Death as a Blessing. The presence of God in ending suffering through death gives way to our subtheme of death as a blessing. This notion of death as a blessing is found in the responses of a woman whose brother was dying.

I: How do you handle visiting the nursing home where, you know, so many people die? How do you handle visiting the nursing home where, you know, so many people die?

R: Well, truthfully, it's to be expected. When I see them getting very ill, you know. And especially in the nursing home where Francis is, there are an awful lot of sick people there. And I handle it all right. I'm used to it. A lot of these people they don't know where they are at, you know. They're not too clear and you can't talk with them very well. So, that's the situation.

I: Does all that death and dying nevertheless affect you?

R: Not really. It's to be expected. I feel it's a blessing for most of them that they are very ill.

The implication here is that, in dying, the ill overcome their illnesses and incapacities. Death is thus a blessing in two ways. First, as the end to confusion and loss of identity, it is also an end to suffering. Second, as it leads to an eternity of existence unhampered by disease and with an integrated physical and spirituality identity in God's world.
Being part of a setting in which suffering and death seem to prevail intensifies the experiences of all stakeholders. Nevertheless, the nursing home acts to emphasize and normalize life through its routines, daily activities, a focus on individuals rather than the collective, its medical focus, and its management of daily time, so that stakeholders are not overwhelmed by the prevalence of dying and death. The central place of religion and spirituality in this setting both sacralizes daily life and gives meaning to death as a transition to eternal life. It is important to note that death is not denied here but is decentered and not focused on as one passage in life's journey just as the nursing home is one brief setting in a much, much larger world. The sister of a woman residing in the nursing home noted how she and her sister have spoken together about dying: "Just that we really believe in our religion. I would feel she would be in Heaven with her husband. When they put someone in the cemetery, I do believe they are really underground...." Informants' responses that highlighted death as a blessing were commonplace. A discussion of a resident's pain along with talk of death as a blessing provides a way towards understanding suffering. One informant discussed the "blessing" of death in relation to a resident she came to know when she visited her mother.

I: Was there any other resident you knew who died here?

R: Yes.

I: Can you tell me about that experience?

R: To them... They were so... I thought it was a blessing for them and their family.

In another instance, the idea of blessing was stated directly about the relative who lived in the nursing home:

I: And when you think of Francis, how do you feel about that?

R: About him dying?

I: Yes.

R: Truthfully, I'd be glad to see him go to a rest, because he's not improving. There's no hope. $\mathrm{He}$ can't do anything for himself. He can't turn over in bed. You know, he has to get somebody to do everything for him except when he gets out in the wheelchair, which is very good...

I: You could understand it if he did go?

R: Very much so, yes. To tell you the truth, I'd be glad to see him go to Heaven.

She said this with sadness, but also with a pragmatic tone. When the option of life is no longer possible, one must turn to another option. Implicit in the statement is that our duty as human beings to enjoy fullness of life in this world. Residents themselves recognized this. One elder told us, "My life is over." In fact, informants' urge towards normalcytowards life-was strong. And although residents did not give up on this life because the afterlife was free of pain and suffering, they recognized that they were not living in the "normal" sense, but marking time. 


\subsection{Theme Two: Discourse about Death and Dying (or Lack Thereof)}

3.2.1. Avoidance of Death Talk. Despite numerous inquiries about death and dying put forth by our research in the nursing home, some informants reported an inability to talk directly about aspects of death and dying with loved ones. They noted that "death" talk was either muted or avoided. Avoidance of talk about dying and death may be salient for the residents' cohort-a cultural generation in which emotions or psychological states were handled privately. The wife of a resident discussed this matter:

I: In general, is your husband pretty open in discussing death or does he avoid that?

R: No. We have never discussed death.

I: And you agree?

R: Yes.

I: Tell me more about that.

R: Well, you see, there's no hope for him getting any better and his senses are so keen and he knows everything that is going on around him. Since there's no hope for a cure, what else is there to face but a happy death...He'd be relieved of all the suffering.

In this case, the respondent reveals that discussion of her husband's state is futile. Both know he "faces" death, and therefore nothing needs to be said. In most cases we investigated there was mutual disinclination to discuss anything around dying and death except the pragmatics, such as funeral arrangements or end-of-life medical intervention. Avoidance of this discussion resulted from discomfort or even from a failure to realize that dying and death could be a topic among loved ones.

In this regard, a salient aspect of life in this nursing home appeared to be that its religious nature helped foster whatever decision a resident made about death talk. For example, nothing more could be required than minimal talk because all residents, family, and many of the staff together accepted an overall spiritual vision of the end of life. This vision was of the role of the nursing home as aiding the transition from life to afterlife. This known transition from life to Heaven was stated by many stakeholders in the nursing home, most usually by family about their loved one, that further discussion of the meaning and nature of the dying process might be unnecessary and its mystery labeled just as mystery and left alone. This topic may not have required much talk for residents. However, as we shall see below, residents did utter concerns about the dying process and even the wish to die. The stakeholders in this nursing home, for the most part, accepted an overall spiritual vision of the end of life. This vision viewed the role of the Catholic nursing home as aiding the transition from life to afterlife. In this light, acceptance of the meaning of suffering or the "why" of dying and death as a mystery is a rational response. Ambiguity, mystery, and uncertainty are aspects of the human condition that give rise to both suffering and faith. We note, however, that faith is not blind or blindly obedient. The most fervent of believers doubt their beliefs at times, fear the unknown, especially the unknown of death, and feel alone and forsaken.

3.2.2. The Statement of Death Claims. The realization that one is very ill or in fact dying may cause residents to assert their desire to die. Such comments appear commonplace, and staff tend to see these as understandable utterances of fear and frustration. One relative of a resident related the following:

I: When he talks about wanting to die, what kind of things does he actually say?

R: He actually says, "I wish I was dead."

Another informant responded to our questions this way:

I: Have you and your sister ever talked about wanting to die?

R: Yes, she has

I: What did she say?

I: What do you say to her when she says that?

I: What do you say to her when she says that?

R: I say, "Cut it out”. I'll say, "I'm much younger than she is and I have a lot of time and she better be there" ... [ha ha ha]

I: What does she say to that?

R: She says, "You're a dreamer..."

I: Is it hard to hear when somebody says they want to die?

R: Well, as I say, "if God takes you, it would be the best if she doesn't suffer. .. I would not want her to suffer like Jim did..."

In this complex dialogue, the informant labels the elder's desire to die as "disgust" with her physical condition. In fact, researchers heard the word "disgust" used as a proxy for wanting to die in several instances. The younger sister responds humorously and reminds the elder of her responsibilities as an older sister. Here, humor and accountability are used to normalize the "negative" feeling of wanting to die. Yet both acknowledge the resident's suffering; the resident, by wanting to die, and the sister, by referring to the extreme suffering of Jim. As shown in many of our dialogues, informants understood that the resident's and their own desire to end the loved one's suffering trumped any "moral wrong" associated with the desire to die.

3.2.3. Death Thoughts versus Religious Activities. The daily routine of the nursing home focuses on everyday life activities, such as eating, medical care, and religious worship. There is much evidence, however, that thoughts of death are induced by the resident's focus on herself. She is aware that this is the last home of all residents; she sees others dying around her. In the field notes of an interview with a dying woman on hospice, the interviewer commented on how this resident attempted to push thoughts of death away. 
Yolanda hopes she would get better. She says: "I pray a lot for a miracle." She prays to St. Joseph and St. Anthony. I ask her: Have you ever thought about dying? She responds: "I try not to. I'm scared. I pray with all my heart and think of other things."

Yolanda is bed-bound and unable to engage with others or enjoy the home's activities. "Thinking" is her primary activity, particularly about her dire situation. Hospice attempts to help her come to terms with dying, but physical pain and discomfort make both solitude and acceptance difficult. She finds some comfort in prayer. Even at the end of her life, her will to live is strong and she continues to pray for a miracle. What is important to note here is that, as we mentioned under the subtheme of the avoidance of death talk, faith does not necessarily lessen the fear of death. Yet, using the same perspective fear does not lessen faith. For all sentient beings, living is normative, important, and what we know. Faith can and usually does include both doubt and hope.

\subsection{Theme Three: Personal Characteristics and Virtues}

3.3.1. Territory of the Unknown. Nursing home stakeholders know that much about life and death is unknown. Despite the fact that nursing homes are considered one's last home, no one can precisely predict the time and manner of a resident's death. For example, a resident's medical status, although usually in a gradual downward path, varies considerably from day to day. Staff reports that residents will have "good days" and "bad days" or even "good mornings" and "bad mornings." Essentially, our unknowingness leaves open a great space for God to fill. In the religious home, it also speaks to the finite nature of our lives, the mystery of our deaths, and the incomprehensibility of God. One family member, a religious sister, told us the following:

I'm a Sister from [name of parish]. So, part of my training has been to deal with that and to be present to the person. I think I have incorporated that into my prayer. The unknown is sort of something I hand over to the Lord. I go in there knowing that God is going to do something. I do not know what it is, but I know it's going to be good. So I go in to comfort the sick person and also their relatives. I pray with them at every Holy Communion. So when I go to the nursing home it's sort of similar. Like I know I'm just with people and that's the important thing. I do not think about sickness or dying or whatever. I try anyway. It's not easy. I really do try to listen to them...I do not even try to handle it. I think I go in with that attitude.

This religious sister and family member through her faith has opened the smaller world of the nursing home to the much larger world of God. It is not merely that she does not know a resident's health condition or what the future holds for them, it is that this knowledge is not available to her; it is stored within the all-knowingness of God [15]. Her words of hope, "God is going to do something" and it is "going to be good," break the barrier between the sacred and profane, replace the nursing home in a much larger context, and rewrite a personal history with an ending hidden in the knowledge of God.

Strength in the Face of Suffering. For everyone, strength is necessary for the commitment to endure everyday life. Residents in the nursing home hold onto life even in suffering, despite their belief that the afterlife will free them from suffering. The desire to show strength in the face of suffering reinforces a commitment to life. In the example below, the informant shows that strength is tied to a sound mind or the ability to reason.

I: Did she show any signs that she was upset?

R: I am certain that she was upset. But it wasn't to the point where you don't get over it. Some say, "What am I living for?" They don't have anybody. My aunt was never like that. She was a strong person until the Alzheimer's got to her.

Staff members and residents will describe those with Alzheimer's disease, but who endure physically, as having strength, or as one informant described her loved one as "a tough old bird." Thus, strength may be thought of by some as a gift from God that individuals must exercise and manipulate. Being strong combines two kinds of ideology. These are: belief in self and trust in God. A beneficent God offers strength to human beings. Together they use this gift for both living and dying.

\subsection{Theme Four: Experiences with Death and Dying}

3.4.1. The Demystification of Death. Some informants found that the experience of watching a loved one die, perhaps particularly in the nursing home, led to (1) a pointed focus on the details of the death of the loved one, (2) a widening perspective about death itself that centered on the dying individual.

The comments of the informant below show both empathy and distance as he discusses a series of deaths of those close to him.

R: It was difficult. It was hard to see somebody suffer. That was the hardest experience. I was with him when he died. And I'm not sure if I was numb or what, but all I was interested in was talking to him, so he would not be afraid, and in letting him know that someone was there and taking care of him. And neither of us knew what would happen. So, basically, it was just like I didn't expect him to die so soon. I just did the best I could. Afterwards, I guess I was, I can't explain, I guess your faith helps you. I felt like I died, too, but I came to life inside myself. My emotions and things took a while.

I: Does all this death and dying at the nursing home affect you personally in any way? 
R: Yes. Sort over the last two and a half years, both my mother and father passed away. If you had asked me this question before then, I would have been a lot more afraid of it than I am now.

This informant uses the preeminent Christian metaphor of death and resurrection as well as the "journey" metaphors of life and death. He peered into the faces of his dying loved ones, traveled to the brink of death with them, and was transformed in the process. Yet, he came to life again, realizing that, because it was not his time or his death, he could not truly experience it.

3.4.2. A Good Death Requires Support. All informants interviewed mentioned that support by family members through the process of dying and death is critical. As noted previously, much of what occurs in the nursing home, such as daily routine or the level of personal care, is dictated by Federal and state regulations. When there is a consensus that a resident is in the dying process, a new protocol emerges; the first priority becomes the patient's care and comfort. Certain staff members may be given the task of sitting with the resident so she will not die alone. Because many of the residents have no children or other family, the work of simply being present to a resident is crucial.

In the following passage, a family member contrasts his/her own perspective of death with that of the dying resident.

I think death is a natural part of life. I think it's easy for me to say because I'm not there, facing it. I do think that with the right amount of care and the right amount of support around it, that could be what you call a right kind of death. How the dying person takes it, I don't know.

This informant recognizes that although she cannot "experience" dying, she can give care and support to one who is and hope that it has brought the dying elder some peace. Networks of positive social support are integral for people experiencing death. They may help diminish the loneliness and fear that attends the dying process $[16,17]$. Studies show that intense fear of being alone at the end of life sometimes drives the dying to request extraordinary medical measures so that "others," even medical personnel, will attend and surround them. This nursing home offers a support system to those who, in other circumstances, or perhaps in other nursing homes, may die alone.

\section{Discussion}

These several themes encapsulate a very great deal of what residents, family, and staff think about death and dying in this Catholic nursing home. These themes suggest that God is present in this nursing home and is in relation to all the death and dying that goes on there. In this context, death may be seen as a blessing in some instances. It may be framed in an ideology in which the events of everyday life and even the event of dying exist in a larger, spiritual context that, at times, can override concerns with daily life and even with pain and suffering.

In this nursing home, a concern with suffering is paramount. For most, suffering might be the largest impediment to a deeper spiritual existence. Certainly, suffering is intrusive to all domains of life. It might be thought to mute prayer and imagination and force the sufferer into the present with an immediate focus on the pained body and the self. It is here, precisely, that suffering is given a meaning by the religiously oriented nursing home. Here, suffering has been "taken over" by the system of beliefs that has enveloped the community. Individual suffering is given meaning by being joined to the deep human well of suffering throughout time and to the spiritual essence of the person-the part that cannot be corrupted, damaged, or destroyed.

While these themes suggest that much of nursing home life is about the search for meaning for all stakeholders, there is another critical element that should be highlighted. In many ways, this nursing home is no different from the others we studied in that it provides residence and care for elders who need a great deal of care, comfort, and protection. There is nothing special or different about the medical care provided to these residents. What is different is the organized opportunity to give the experience of suffering a different meaning than one might regularly attribute to it. The spiritual environment offers the resident and her family members a different way to think about suffering and a different, more inclusive and more powerful context for living while dying. It offers residents a meaningful choice about how to imagine their last days. It offers something else other than the immediacy of the body. Even those with dementing illness are brought to participate in daily Mass and receive the Eucharist, which is thought to give grace and strength to body and soul, or may be visited by clergy, or involved in religious discussion.

What goes on in this setting can be thought of in another way. Given the structure of this nursing home, the individualism that is so much a characteristic of American life and is something that is brought by residents and their families to the nursing home when they arrive there can be supplanted by the attributes of a spiritual community. This is very important because, in a sense, individualism does not work well in suffering. In such instances, individualism is bifurcated because, on the one hand, intrusive suffering allows the individual few competing thoughts except of suffering and little control over her own body. It is here that the individual may be thought to be broken down and lost and her integrity as an individual falters. Yet, in this community, the individual is thought of as a unity of body, mind, and spirit. It is ironic then that, in suffering in the context of the spiritual collective, the individual is preserved.

\section{Acknowledgment}

The data discussed in this paper were gathered in a research project entitled Bereavement in Long-Term Care supported by the National Institute on Aging (R. Rubinstein, PI; AG013993). The authors are grateful to NIA for its support of 
this research. Interviews and fieldwork on which this paper is based were conducted by Anne Bower, Miriam Moss, Sidney Moss, and Robert L. Rubinstein.

\section{References}

[1] V. G. Cicirelli, Older Adults' Views on Death, Springer, New York, NY, USA, 2006.

[2] I. R. Hallberg, "Death and dying from old people's point of view. A literature review," Aging-Clinical and Experimental Research, vol. 16, no. 2, pp. 87-103, 2004.

[3] M. S. Moss, "End of life in nursing homes," in Annual Review of Gerontology and Geriatrics, Vol. 20, M. P. Lawton, Ed., pp. 224-258, Springer, New York, NY, USA, 2001.

[4] S. Z. Moss and M. S. Moss, "Nursing home staff reactions to resident deaths," in Disenfranchised Grief: New Directions, Challenges, and Strategies for Practice, K. J. Doka, Ed., chapter 13, pp. 197-216, Research Press, Champaign, Ill, USA, 2002.

[5] S. Z. Moss, M. S. Moss, H. K. Black, and R. L. Rubinstein, "How family members respond to residents' wish to die," Omega, vol. 51, no. 4, pp. 301-321, 2005.

[6] H. K. Black, "Questions I now ask: spirituality in the liminal environment of assisted living," Journal of Aging Studies, vol. 20, no. 1, pp. 67-78, 2006.

[7] H. K. Black, "The sacred self: suffering narratives in old age," Omega, vol. 53, no. 1-2, pp. 69-85, 2006.

[8] H. K. Black, "How the non-religious experience and witness dying and death: case studies," Journal of Religion, Spirituality and Aging, vol. 19, no. 2, pp. 67-85, 2007.

[9] H. K. Black, "Is pain suffering? A case study," International Journal of Aging and Human Development, vol. 64, no. 1, pp. 33-45, 2007.

[10] N. Krause and C. G. Ellison, "The doubting process: a longitudinal study of the precipitants and consequences of religious doubt in older adults," Journal for the Scientific Study of Religion, vol. 48, no. 2, pp. 293-312, 2009.

[11] C. Aquilina and J. C. Hughes, "The return of the living dead: agency lost and found?" in Dementia: Mind, Meaning, and the Person, J. C. Hughes, S. J. Louw, and S. R. Sabat, Eds., pp. 287302, Oxford University Press, Oxford, UK, 2006.

[12] H. K. Black, “The person in alzheimer's disease," in Religion in America, L. Bregman, Ed., Praeger Publications, Oxford, UK, 2010.

[13] C. L. Johnson and B. M. Barer, Life Beyond 85 Years: The Aura of Survivorship, Springer, New York, NY, USA, 1997.

[14] F. C. Powell and J. A. Thorson, "Constructions of death among those high in intrinsic religious motivation: a factor-analytic study," Death Studies, vol. 15, no. 2, pp. 131-138, 1991.

[15] H. K. Black and R. L. Rubinstein, Old Souls: Aged Women, Poverty, and the Experience of God, Aldine DeGruyter, New York, NY, USA.

[16] A. Besser and B. Priel, "Attachment, depression, and fear of death in older adults: the roles of neediness and perceived availability of social support," Personality \& Individual Differences, vol. 44, no. 8, pp. 1711-1725, 2008.

[17] R. A. Kalish, Death, Grief, and Caring Relationships, Brooks/Cole, Monterey, Calif, USA, 1985. 


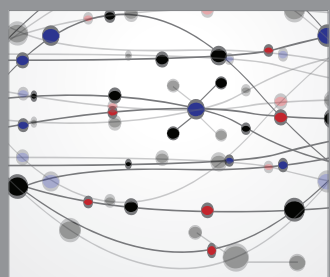

The Scientific World Journal
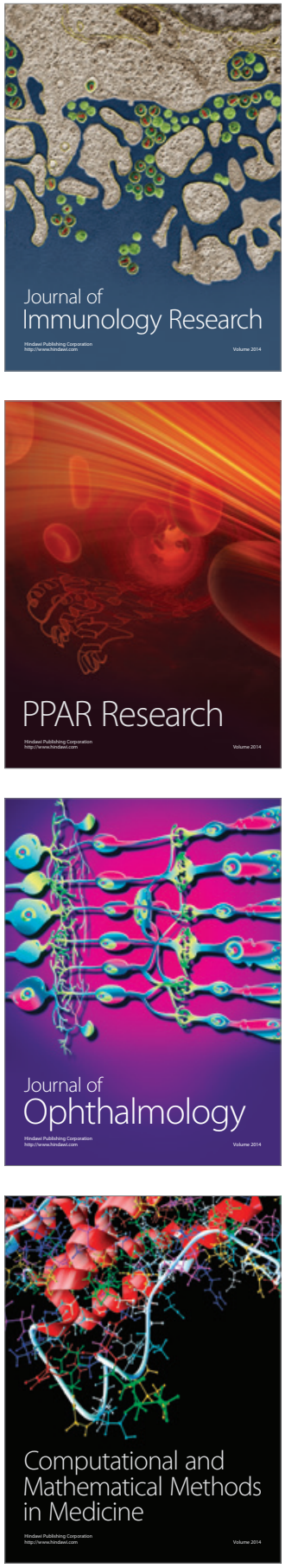

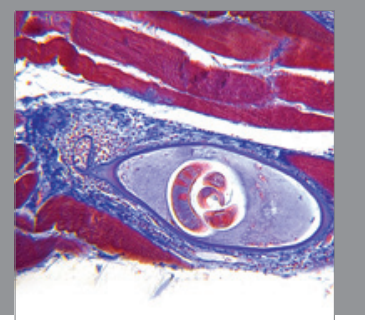

Gastroenterology

Research and Practice
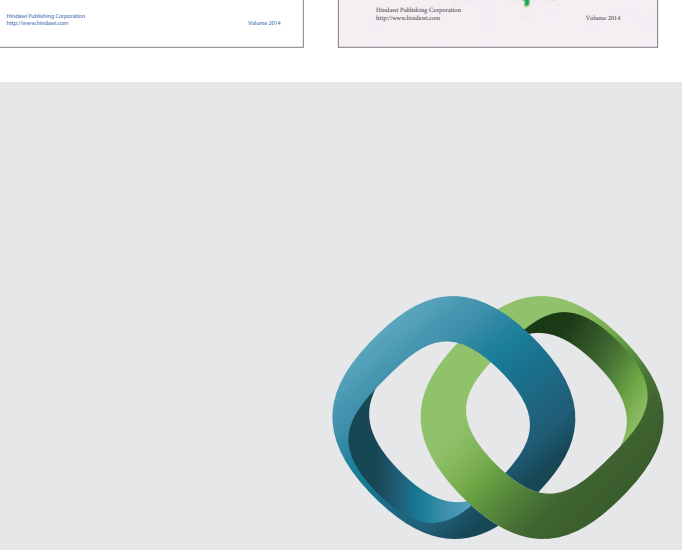

\section{Hindawi}

Submit your manuscripts at

http://www.hindawi.com
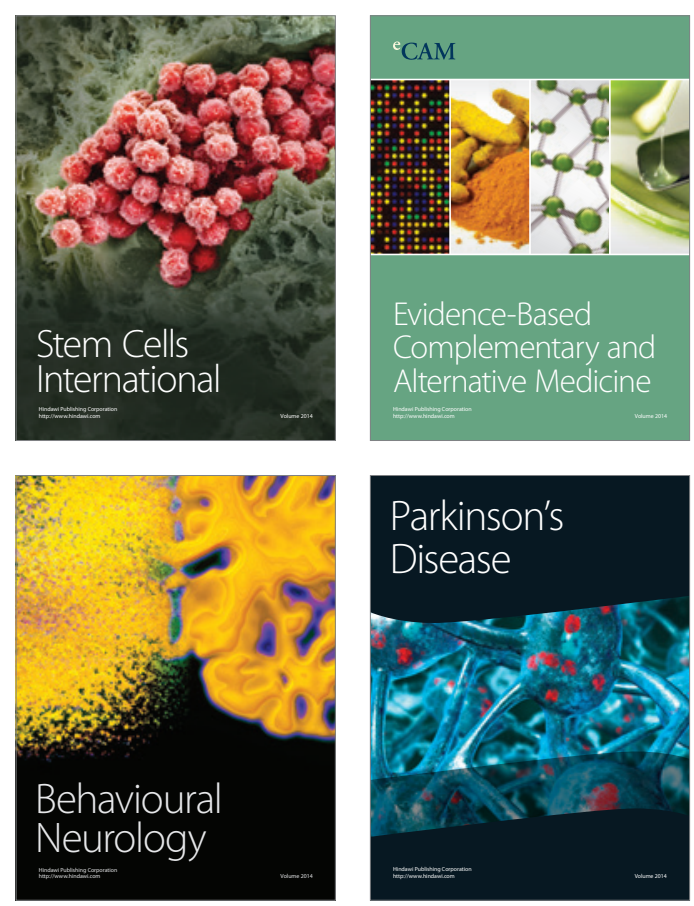

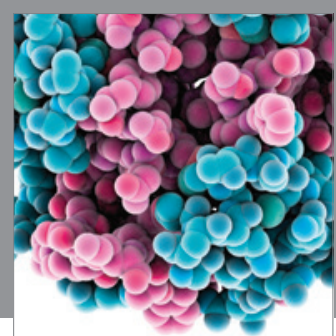

Journal of
Diabetes Research

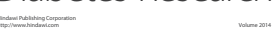

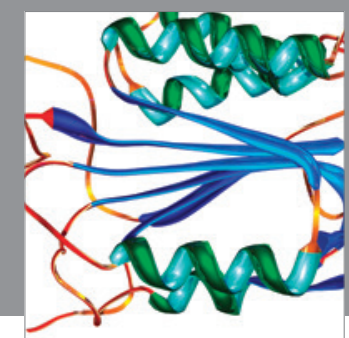

Disease Markers
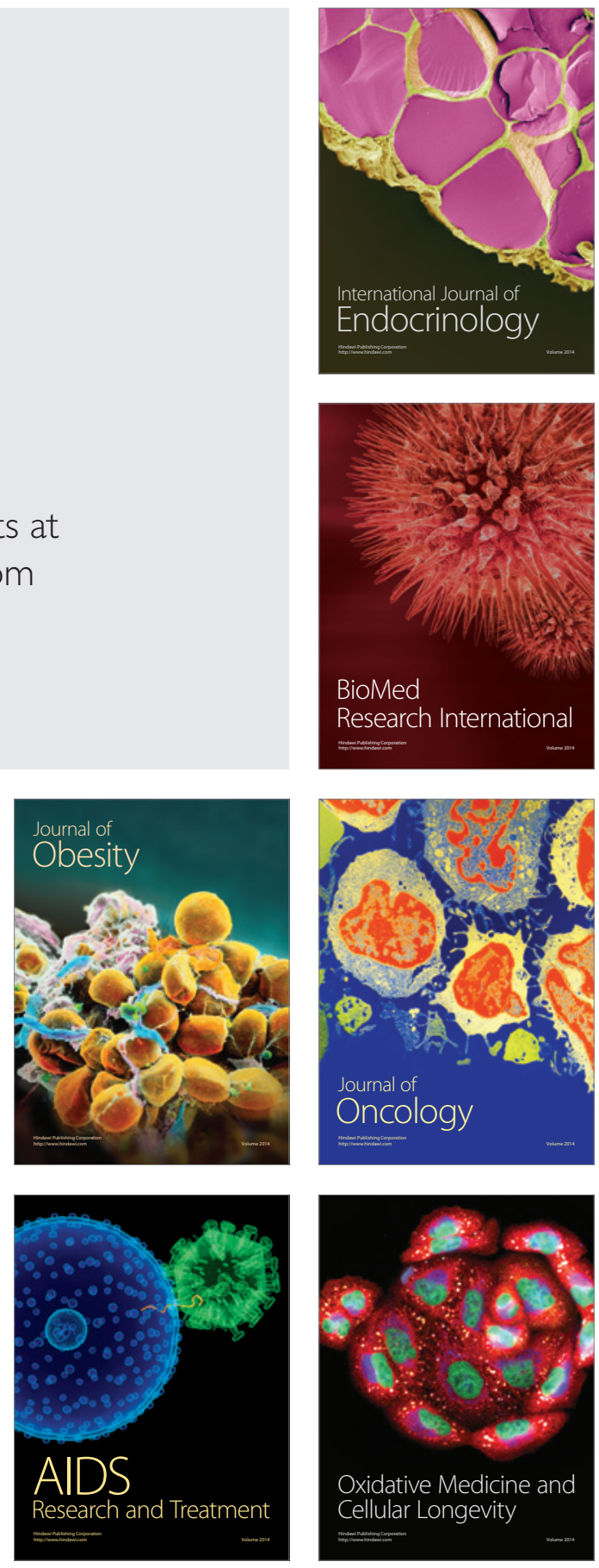